\title{
Long-term effects of linoleic-acid-enriched diet on albuminuria and lipid levels in Type 1 (insulin-dependent) diabetic patients with elevated urinary albumin excretion
}

\author{
R.P.F. Dullaart ${ }^{1}$, B.J. Beusekamp ${ }^{2}$, S. Meijer ${ }^{3}$, K.Hoogenberg ${ }^{1}$, J.J. van Doormaal ${ }^{1}$ and W.J.Sluiter $^{1}$ \\ Departments of ${ }^{1}$ Endocrinology, ${ }^{2}$ Dietetics and ${ }^{3}$ Nephrology, University Hospital Groningen, The Netherlands
}

\begin{abstract}
Summary. We conducted a 2-year prospective randomised study to investigate the effects of a linoleic-acid-enriched diet on albuminuria and lipid levels in Type 1 (insulin-dependent) diabetic patients with elevated urinary albumin excretion (overnight urinary albumin excretion rate between 10 and $200 \mu \mathrm{g} / \mathrm{min}$ ). Thirty-eight patients were randomly assigned to increase dietary polyunsaturated:saturated fatty acids ratio to 1.0 by replacement of saturated fat with linoleicacid-rich products ( $n=18$, two dropouts, analysis was performed in $n=16)$ or to continue their usual diet $(n=20)$. The total fat and protein content of the diet was unaltered. Clinical characteristics, albuminuria, blood pressure, glomerular filtration rate, metabolic control and dietary composition were similar in the two groups at baseline. In the high linoleic acid diet group, linoleic intake rose from $7 \pm 4$ to $11 \pm 2$ energy $\%$ and polyunsaturated:saturated fatty acids ratio rose from $0.60 \pm 0.28$ to $0.96 \pm 0.16$ ( $p<0.001$ compared to usual diet group). The median increase albuminuria was $58 \%$ (95\% confidence interval, 13 to 109) during the first year $(p<0.02)$ and $55 \%$ (95\% confidence interval, 11 to 127$)$ $(p<0.01)$ during the second year. Glomerular filtration rate
\end{abstract}

remained unaltered and filtration fraction tended to rise ( $p<0.05$ compared to usual diet group). In the usual diet group, albuminuria did not significantly increase by $16 \%$ ( $95 \%$ confidence interval, -17 to 38 ) and glomerular filtration rate declined during the second year. Blood pressure tended to rise similarly in both groups. Multiple regression analysis showed an independent effect of the high linoleic acid diet on the progression of albuminuria as well as the lack of decrease in glomerular filtration rate. Low density lipoprotein cholesterol and apolipoprotein $\mathrm{B}$ levels decreased in the high linoleic acid diet group $(p<0.05)$. High density lipoprotein cholesterol declined in both groups $(p<0.05)$. It is concluded that a linoleic-acid-enriched diet reduces atherogenic lipoproteins but does not have a beneficial effect on and might even promote renal functional abnormalities in Type 1 diabetic patients with elevated urinary albumin excretion.

Key words: Microalbuminuria, lipoproteins, linoleic acid, polyunsaturated fatty acids, diet, Type 1 (insulin-dependent) diabetes mellitus.
The presence of microalbuminuria in Type 1 (insulin-dependent) diabetic patients is a sensitive predictor of future development of diabetic nephropathy [1-3]. In patients with nephropathy the risk of cardiovascular mortality is greatly increased [4]. Microalbuminuria does not only imply the presence of renal involvement in diabetes mellitus, but is also associated with generalised vascular damage as indicated by increased transcapillary leakage of albumin and markers of endothelial lesions [5]. In addition, several studies have shown that alterations in plasma lipoproteins such as elevated levels of LDL cholesterol and apolipoprotein B and low levels of HDL cholesterol can be demonstrated in Type 1 diabetic patients with microalbuminuria [6-10]. These unfavourable lipoprotein abnormalities will contribute to the increased cardiovascular risk and warrant dietary intervention in such patients.
One aspect of the dietary recommendations for diabetic patients is to replace saturated-fatty-acid-rich products with linoleic-acid-rich nutrients [11]. However, the possible renal effects of an increased intake of linoleic acid in Type 1 diabetic patients are unknown. In normal subjects, a high linoleic acid diet has been reported to stimulate creatinine clearance, possibly through an enhanced synthesis of vasodilatory prostaglandins [12]. The reported effects of dietary linoleic acid in various animal models of experimental renal disease are controversial. In immune complex nephritis essential fatty acid deficiency was associated with prolonged survival [13], but this could not be confirmed in another study [14]. When partial nephrectomy was employed as a model of chronic renal failure, a high linoleic acid diet improved renal function and reduced proteinuria [15-17]. 
The purpose of the present study was to investigate the long-term effects of dietary advice to increase linoleic acid intake at the expense of saturated fatty acids, achieving a polyunsaturated: saturated fatty acids ratio of 1.0 , on albuminuria and lipoprotein levels in Type 1 diabetic patients with elevated urinary albumin excretion.

\section{Subjects and methods}

\section{Patients}

Patients with Type 1 diabetes and elevated urinary albumin excretion were recruited from the out-patient clinic. All patients suffered from ketosis-prone diabetes and were deemed insulin-dependent on clinical grounds. Patients with a mean urinary albumin excretion rate (UalbV) of between 10 and $200 \mu \mathrm{g} / \mathrm{min}$, determined in three consecutive timed overnight urine collections, and with sterile urine cultures were selected for the study. Three urine collections were used for classifying patients because of the high coefficient of variation of UalbV $[18,19]$. These cut-off points were chosen since $10 \mu \mathrm{g} / \mathrm{min}$ represents the upper normal limit of UalbV (above the 97.5 th percentile for 50 healthy control subjects) in our clinic, whereas levels above $200 \mu \mathrm{g} / \mathrm{min}$ indicate diabetic nephropathy. The lower cut-off level of UalbV of $10 \mu \mathrm{g} / \mathrm{min}$ is comparable to previous studies showing an upper normal range in overnight collections of $7 \mu \mathrm{g} / \mathrm{min}$ [18] and $12 \mu \mathrm{g} / \mathrm{min}$ [20] in non-diabetic subjects. This cut-off point is however lower than the proposed level of $20 \mu \mathrm{g} / \mathrm{min}$ ( used to define microalbuminuria as a risk marker of diabetic nephropathy $[3,5]$. Other criteria to be eligible for participation in the study were an age between 21 and 65 years, duration of diabetes of at least 5 years, serum creatinine $\leq 120 \mu \mathrm{mol} / \mathrm{l}$ and the patients' ability to monitor their blood glucose levels. Exclusion criteria were a history of other renal disease or renal tract abnormality, hypertension (systolic blood pressure $\geq 160 \mathrm{mmHg}$ and/or diastolic blood pressure $\geq 95 \mathrm{~mm} \mathrm{Hg}$ ) unless adequately treated, change in antihypertensive medication within 3 months before randomisation, pregnancy and liver disease. The participants were randomised within 3 months of selection. All participating patients gave their oral informed consent. The study was reviewed and approved by the local medical ethics committee.

\section{Study design}

The study was a 2 -year randomised prospective trial. The patients were randomly assigned to increase the dietary intake of linoleic acid at the expense of saturated fatty acids achieving a polyunsaturated:saturated fatty acids ratio ( $\mathrm{P}: \mathrm{S}$ ratio) close to 1.0 (high linoleic acid diet: HLAD) or to continue their usual diet (UD). The patients were stratified according to sex and randomised using blocks of ten men and six women. Assignment took place using opaque sealed envelopes. The objectives of the study were albuminuria and lipid levels. In addition, renal haemodynamics (glomerular filtration rate (GFR), effective renal plasma flow (ERPF) and filtration fraction), blood pressure and metabolic control were documented.

Renal haemodynamics were measured at baseline (shortly before randomisation) and after 1 and 2 years. The other determinants were measured at baseline and after $1.5,4,8,12,16,20$ and 24 months. The required sample size of the study was estimated on the basis of the high coefficient of variation of UalbV of $43.5 \%$ [19] with three overnight timed urine samples collected on each occasion. It was calculated that 14 participants in each group were required to observe an inter-group significant difference in change of UalbV of $50 \%$ and an intra-group change of $37 \%$ at a two-sided $p<0.05$, with a power of 0.85 .

\section{Dietary assessment}

The dietary assessments were performed by the same dietician. The patients assigned to HLAD were advised to replace butter or saturated margarines by polyunsaturated margarines and to restrict the intake of saturated fat from meat and milk products. Cholesterol intake was also reduced as a result of the restricted intake of animal fat. All participants were urged not to alter the total fat and protein content of the diet. Dietary sodium was unchanged. The diet was isocaloric for each patient. A complete dietary history was documented at baseline and after 1 and 2 years. Dietary records were obtained using the recall technique, covering 1 week (including a weekend) and cross-checked with each patient [21]. The composition of the diets was analysed with a computer assisted Nutrient Data Base [22]. At every visit nutritional advice was given as necessary. To confirm the increase in dietary $P: S$ ratio in HLAD, the fatty acid composition of plasma cholesteryl esters was measured at baseline and at the end of the study. For this purpose the amount of linoleic acid $(18: 2 \mathrm{c}, \omega 6)$, oleic acid $(18: 1 \mathrm{c}, \omega 9)$ and the linoleic acid: oleic acid ratio was documented [23]. Dietary protein intake was also calculated by the use of 24-h urinary urea excretion [24].

\section{Clinical and laboratory measurements}

The GFR and ERPF were measured simultaneously using ${ }^{125}$ I-iothalamate and ${ }^{131}$ I-hippuran, respectively, according to a previously described procedure $[25,26]$. On each occasion the patients were studied after an overnight fast in the supine position starting at 08.00 hours. The morning insulin dose was withheld. To prevent ketosis the patients received an intravenous glucose solution to which regular acting insulin (Actrapid H.M., Novo-Nordisk, Bagsvaerd, Denmark) was added. The blood glucose levels were corrected to between 4.4 and $8.3 \mathrm{mmol} /$. After a 4 -h period to normalise and stabilise blood glucose levels, GFR and ERPF were determined over a 2-h clearance period. The filtration fraction was calculated as the GFR/ERPF tatio in percent. GFR and ERPF were adjusted to $1.73 \mathrm{~m}^{2}$ of body surface area. Blood pressure was measured using a standard sphygmomanometer (Baumanometer, W.A. Braun Inc., New York, NY, USA). After a 10-min rest the sitting blood pressure was measured three times on both arms. Korotkoff phase 5 was taken as the diastolic blood pressure. The recordings were averaged for computation. The mean arterial pressure (MAP) was calculated as $0.67 \mathrm{x}$ diastolic pressure $+0.33 \mathrm{x}$ systolic pressure. Retinopathy was assessed by fundoscopy through dilated pupils and classified for the worst eye as absent, background or proliferative.

At every visit three consecutive timed overnight urine samples and one 24-h urine specimen were collected. Serum and EDTA-anticoagulated plasma samples were taken after an overnight fast. Urinary albumin was measured by a double-antibody radioimmunoassay (cat no $\mathrm{KHAD}_{2}$, Diagnostic Products Corporation, Apeldoorn, The Netherlands). The intra- and intercoefficients of variation were 2.3 and $7.7 \%$, respectively. Urinary urea and serum creatinine, protein and albumin were measured on a SMAC II autoanalyser (Technicon Instruments Inc., Tarrytown, NY, USA). Haemoglobin $A_{1}$ $\left(\mathrm{HbA}_{1}\right)$ was measured by colorimetry [27] (reference values: 4.5 to $5.8 \%$ ). One 8 -sample-based 24 -h blood glucose profile (read with reagent strips) was documented by the patients at least every 4 weeks. Lipids were measured in unfrozen serum and in the HDLcontaining supernatant fraction after precipitation of apolipoprotein B-containing lipoproteins with sodium phosphotungstate and magnesium chloride [28]. Cholesterol and triglyceride were measured enzymatically using automated methods [29, 30]. LDL and VLDL cholesterol were calculated by the Friedewald formula [31]. Serum samples for apolipoproteins and plasma samples for cholesteryl ester-derived fatty acid determinations were frozen at $-20^{\circ} \mathrm{C}$ until assay. Serum apolipoprotein $A_{1}$ and $B$ were measured by immunoturbidimetry on a Multistat I centrifugal analyser (Instrumentation Laboratories, IJsselstein, The Netherlands) using commercially available kits (cat no 726478 and 726494 , respectively, Boehringer Mannheim, Almere, The Netherlands). Plasma choles- 
teryl ester-derived fatty acids were measured using capillary gas chromatography as previously described [32].

\section{Statistical analysis}

The data obtained during the first and the second year after randomisation were pooled for statistical analysis. Comparison of baseline variables and of differences in change between the groups was performed by the Wilcoxon-test for unpaired observations. Changes in variables within a group were analysed by two-way analysis of variance according to Friedman [33] using the baseline measurement as reference point. Adjustment for multiple comparisons was carried out using Duncan's method [34]. Differences in prevalence of variables among groups were analysed by chi-square statistics. Relative risks ( $95 \%$ confidence interval, $\mathrm{CI}$ ) were calculated for progression of albuminuria. Multiple regression analysis was carried out to evaluate the independent contribution of parameters. Baseline UalbV is expressed as median (interquartile ranges); changes in UalbV are given in percent change (median, $95 \% \mathrm{CI}$ ). Other data are expressed as mean \pm SD or mean \pm SEM. $p$ values less than 0.05 were considered to be significant.

\section{Results}

\section{Patients}

Of the 38 randomised patients 18 were assigned to the HLAD group and 20 to the UD group. Two patients assigned to HLAD were excluded from analysis because of pregnancy and a decision not to participate further. The baseline clinical characteristics of the remaining 36 patients are shown in Table 1 . The two groups were closely comparable with respect to clinical parameters and serum creatinine. The UalbV values obtained at selection were not different $(p>0.70$, Table 1$)$. The prevalence of retinopathy and cardiovascular disease as well as the proportion of patients who smoked cigarettes was similar in both groups. In the HLAD group, one patient was treated for hypertension with a diuretic throughout the study. In the

Table 1. Baseline clinical characteristics

\begin{tabular}{lll}
\hline & $\begin{array}{l}\text { HLAD } \\
(n=16)^{\mathrm{a}}\end{array}$ & $\begin{array}{l}\text { UD } \\
(n=20)^{\mathrm{a}}\end{array}$ \\
\hline Age (years) & $44 \pm 12$ & $41 \pm 14$ \\
Duration of diabetes (years) & $24 \pm 11$ & $20 \pm 10$ \\
Sex (males/females) & $13 / 3$ & $15 / 5$ \\
Body mass index $\left(\mathrm{kg} / \mathrm{m}^{2}\right)$ & $24.1 \pm 2.4$ & $23.8 \pm 2.3$ \\
UalbV $(\mu \mathrm{g} / \mathrm{min})^{\mathrm{b}}$ & $15(13-65)$ & $26(15-40)$ \\
Serum creatinine $(\mu \mathrm{mol} / \mathrm{l})$ & $88 \pm 16$ & $85 \pm 17$ \\
Antihypertensive treatment $(n)$ & 1 & 2 \\
Cardiovascular disease $(n)$ & 5 & 4 \\
Retinopathy $(\mathrm{O} / \mathrm{B} / \mathrm{P})^{\mathrm{c}}$ & $2 / 8 / 6$ & $5 / 12 / 3$ \\
Cigarette smokers $(n)$ & 8 & 11 \\
\hline
\end{tabular}

${ }^{a}$ HLAD, Type 1 (insulin-dependent) diabetic patients assigned to high linoleic acid diet; UD, Type 1 diabetic patients assigned to usual diet; ${ }^{\text {b }}$ UalbV, urinary albumin excretion rate; values at selection of patients; ${ }^{\mathrm{c}}$ Retinopathy: 0 , absent; $\mathrm{B}$, background; $\mathrm{P}$, proliferative. Results are given as mean $\pm \mathrm{SD}$, except UalbV as median (interquartile ranges)
Table 2. Composition of the diet

\begin{tabular}{|c|c|c|}
\hline & HLAD $(n=16)^{2}$ & UD $(n=20)^{\mathrm{a}}$ \\
\hline $\begin{array}{l}\text { Energy (Megajoules/day) } \\
\text { baseline } \\
1 \text { year } \\
2 \text { years }\end{array}$ & $\begin{array}{l}8.25 \pm 2.24 \\
8.01 \pm 2.15 \\
7.43 \pm 2.02^{c}\end{array}$ & $\begin{array}{l}9.04 \pm 2.75 \\
8.42 \pm 2.60 \\
8.48 \pm 2.80\end{array}$ \\
\hline $\begin{array}{l}\text { Carbohydrates (Energy \%) } \\
\text { baseline } \\
1 \text { year } \\
2 \text { years }\end{array}$ & $\begin{array}{l}42 \pm 7 \\
42 \pm 7 \\
43 \pm 4\end{array}$ & $\begin{array}{l}39 \pm 7 \\
41 \pm 8 \\
41 \pm 7\end{array}$ \\
\hline $\begin{array}{l}\text { Protein (Energy \%) } \\
\text { baseline } \\
1 \text { year } \\
2 \text { years }\end{array}$ & $\begin{array}{l}18 \pm 2 \\
18 \pm 1 \\
18 \pm 4\end{array}$ & $\begin{array}{l}17 \pm 4 \\
16 \pm 3 \\
17 \pm 3\end{array}$ \\
\hline $\begin{array}{l}\text { Total fat }(\text { Energy } \%) \\
\text { baseline } \\
1 \text { year } \\
2 \text { years }\end{array}$ & $\begin{array}{l}39 \pm 6 \\
39 \pm 6 \\
37 \pm 4\end{array}$ & $\begin{array}{l}42 \pm 7 \\
41 \pm 7 \\
40 \pm 7\end{array}$ \\
\hline $\begin{array}{l}\text { Saturated fatty acids (Energy \%) } \\
\text { baseline } \\
1 \text { year } \\
2 \text { years }\end{array}$ & $\begin{array}{l}16 \pm 4 \\
13 \pm 2^{\mathrm{b}, \mathrm{e}} \\
13 \pm 2^{\mathrm{b}, \mathrm{f}}\end{array}$ & $\begin{array}{l}16 \pm 3 \\
16 \pm 3 \\
16 \pm 3\end{array}$ \\
\hline $\begin{array}{l}\text { Linoleic acid (Energy \%) } \\
\text { baseline } \\
1 \text { year } \\
2 \text { years }\end{array}$ & $\begin{array}{c}7 \pm 4 \\
12 \pm 3^{\mathrm{d}, \mathrm{g}} \\
11 \pm 2^{\mathrm{d}, \mathrm{g}}\end{array}$ & $\begin{array}{l}7 \pm 4 \\
7 \pm 3 \\
7 \pm 3\end{array}$ \\
\hline $\begin{array}{l}\text { Polyunsaturated: saturated fatty a } \\
\text { baseline } \\
1 \text { year } \\
2 \text { years }\end{array}$ & $\begin{array}{l}\text { ids ratio } \\
\quad 0.60 \pm 0.28 \\
1.00 \pm 0.18^{\mathrm{d}, \mathrm{g}} \\
0.96 \pm 0.16^{\mathrm{d}, \mathrm{g}}\end{array}$ & $\begin{array}{l}0.59 \pm 0.28 \\
0.59 \pm 0.22 \\
0.56 \pm 0.25\end{array}$ \\
\hline $\begin{array}{l}\text { Cholesterol }(m g / \text { day }) \\
\text { baseline } \\
1 \text { year } \\
2 \text { years }\end{array}$ & $\begin{array}{l}283 \pm 110 \\
197 \pm 74^{d} \\
174 \pm 49^{d}\end{array}$ & $\begin{array}{l}266 \pm 116 \\
240 \pm 115^{b} \\
245 \pm 120\end{array}$ \\
\hline $\begin{array}{l}\text { Dietary fibre ( } g / \text { day) } \\
\text { baseline } \\
1 \text { year } \\
2 \text { years }\end{array}$ & $\begin{array}{l}29 \pm 8 \\
29 \pm 8 \\
29 \pm 7\end{array}$ & $\begin{array}{l}33 \pm 9 \\
32 \pm 10 \\
32 \pm 10\end{array}$ \\
\hline
\end{tabular}

${ }^{a}$ HLAD, Type 1 (insulin-dependent) diabetic patients assigned to high linoleic acid diet; UD, Type 1 diabetic patients assigned to usual diet; ${ }^{b} p<0.05$ compared to baseline; ${ }^{c} p<0.01$ compared to baseline; ${ }^{\mathrm{d}} p<0.001$ compared to baseline; ${ }^{\mathrm{e}}$ compared to UD, $p<0.05 ;{ }^{f}$ compared to UD, $p<0.01 ;^{\mathrm{g}}$ compared to UD, $p<0.001$. Results are given as mean \pm SD

UD group, one patient used a diuretic to which a betablocker was added after 12 months and another patient used a beta-blocker for hypertension. Two women in each group were using contraceptive drugs. The participants were urged not to use non-steroidal anti-inflammatory drugs during the study.

\section{Diet}

The composition of the diets as assessed by dietary recall is shown in Table 2. At baseline, energy and nutrient intake were similar in the two groups. Total energy intake decreased in the HLAD group after 2 years. Linoleic acid intake increased in the HLAD group and was higher than in the UD group at 1 and 2 years. This rise in linoleic acid intake was achieved by a reduction in the intake of saturated fat and resulted in the recommended $\mathrm{P}: \mathrm{S}$ ratio close 
Table 3. Linoleic acid and oleic acid content of plasma cholesteryl esters

\begin{tabular}{llll}
\hline & $\begin{array}{l}\operatorname{HLAD}(n=16)^{\mathrm{a}} \\
\text { baseline }\end{array}$ & 2 years & $\begin{array}{l}\text { UD }(n=20)^{\mathrm{a}} \\
\text { baseline }\end{array}$ \\
\hline $\begin{array}{l}\text { Linoleic acid }(\mathrm{mol} \%) \\
(18: 2 \mathrm{c}, \omega 6)\end{array}$ & $60.30 \pm 4.76$ & $62.18 \pm 4.15^{\mathrm{d}}$ & $57.47 \pm 6.44$ \\
$\begin{array}{l}\text { Oleic acid }(\mathrm{mol} \%) \\
(18: 1 \mathrm{c}, \omega 9)\end{array}$ & $15.58 \pm 2.42$ & $13.67 \pm 1.84^{\mathrm{c}, \mathrm{d}}$ & $17.47 \pm 2.89$ \\
$\begin{array}{l}\text { Linoleic acid: } \\
\text { oleic acid ratio } \\
(\mathrm{mol} / \mathrm{mol})\end{array}$ & $3.99 \pm 0.87$ & $4.65 \pm 0.85^{\mathrm{b}, \mathrm{d}}$ & $3.43 \pm 0.91$ \\
\hline
\end{tabular}

${ }^{a}$ HLAD, Type 1 (insulin-dependent) diabetic patients assigned to high linoleic acid diet; UD, Type 1 diabetic patients assigned to usual diet;

${ }^{\mathrm{b}} p<0.05$ compared to baseline; ${ }^{\mathrm{c}} p<0.02$ compared to baseline; ${ }^{\mathrm{d}} p<0.01$ compared to UD. Results are given as mean $\pm \mathrm{SD}$

to 1.0. In the UD group, the P: S ratio was unchanged. Dietary cholesterol intake was reduced in the HLAD group and slightly so in the UD group. In both groups, dietary fibre intake was unchanged.

Plasma cholesteryl ester fatty acid analysis substantiated the increase in dietary $P: S$ ratio in the HLAD group (Table 3). In this group, linoleic acid tended to increase $(p<0.10)$ and oleic acid decreased, resulting in a higher linoleic acid: oleic acid ratio after 2 years, whereas in the UD group no significant changes were found in these parameters. On the basis of 24 -h urinary urea excretion, dietary protein intake was comparable in the two groups at baseline and did not change significantly during the study (HLAD: $0.99 \pm 0.25,1.00 \pm 0.25$ and $0.99 \pm 0.24 \mathrm{~g} \cdot \mathrm{kg}$ body weight $^{-1} \cdot$ day $^{-1}$, NS; and UD: $1.12 \pm 0.24,1.09 \pm 0.22$ and $1.07 \pm 0.22 \mathrm{~g} \cdot \mathrm{kg}$ body weight ${ }^{-1} \cdot \mathrm{day}^{-1}$, NS, at baseline and during the first and the second year of the study, respectively).

\section{Albuminuria, blood pressure and renal haemodynamics}

At baseline UalbV was not significantly different in the HLAD group (17(12-33) $\mu \mathrm{g} / \mathrm{min}$ (median (interquartile ranges) ) compared with the UD group (26(13-47) $\mu \mathrm{g} / \mathrm{min}$ ) $(p>0.80)$.In HLAD, UalbV rose to $37(14-72) \mu \mathrm{g} / \mathrm{min}$ during the first year $(p<0.02)$ and to $33(17-65) \mu \mathrm{g} / \mathrm{min}$ during the second year $(p<0.01)$. In UD, UalbV was $19(11-$ 45) $\mu \mathrm{g} / \mathrm{min}$ during the first year and $25(11-79) \mu \mathrm{g} / \mathrm{min}$ during the second year $(p>0.30)$. Alterations in UalbV, expressed as percent change from baseline during the first and the second year of the study are shown in Figure 1, upper panel. In the HLAD group, UalbV increased by $58 \%$ (95\% CI, 13 to 109 ) (median, $95 \%$ CI) during the first year $(p<0.02)$. UalbVwas $55 \%$ ( $95 \%$ CI, 11 to 127$)$ higher in this group during the second year $(p<0.01)$. In the UD group, UalbV did not increase significantly $(16 \%$ ( $95 \% \mathrm{CI}$, -17 to 38 ) during the second year). Furthermore, the increase in UalbV in the HLAD group during the first year was significantly different from the change in UalbV in the UD group $(p<0.05)$. At baseline, seven of the 16 patients assigned to HLAD and 13 of the 20 patients assigned to UD had UalbV $>20 \mu \mathrm{g} / \mathrm{min}(p>0.30)$. In the subset of patients with baseline $\mathrm{UalbV}>20 \mu \mathrm{g} / \mathrm{min}$ the risk for progression of albuminuria waselevated in the HLAD groupcompared with the UD group with a relative risk of $3.10(95 \% \mathrm{CI}, 1.03$ to 9.28$)$ during the first year $(p<0.05)$ and of $1.33(95 \% \mathrm{CI}$,
0.67 to 2.64 ) during the second year. The HLAD patients with baseline UalbV $<20 \mu \mathrm{g} / \mathrm{min}$ showed a similar trend in progression of albuminuria. UalbV increased in eight of the nine HLAD patients and in three of the seven UD patients during the second year $(p<0.03$ for comparison of UalbV values).

The MAP was not different in the groups at baseline and rose similarly in both groups (Fig. 1, lower panel). To clarify the effect of assignment to HLAD and blood pressure on the progression of albuminuria, the patients were divided according to their average MAP during the study into subgroups with MAP $\leq 95 \mathrm{~mm} \mathrm{Hg}$ and $\mathrm{MAP}>95 \mathrm{~mm} \mathrm{Hg}$. This cut-off level was arbitrarily chosen on the basis of an average MAP of $95 \mathrm{~mm} \mathrm{Hg}$ in the entire study population during the 2 years of study. The risk for progression of albuminuria in the various subgroups was compared to the UD patients with a MAP $\leq 95 \mathrm{~mm} \mathrm{Hg}$. As is shown in Table 4 the risk for progression of albuminuria, as measured in the second year, was significantly elevated in HLAD patients with MAP $\leq 95 \mathrm{mmHg}$. When MAP during the study was above $95 \mathrm{~mm} \mathrm{Hg}$, the risk or progression of albuminuria was similarly elevated in both groups.
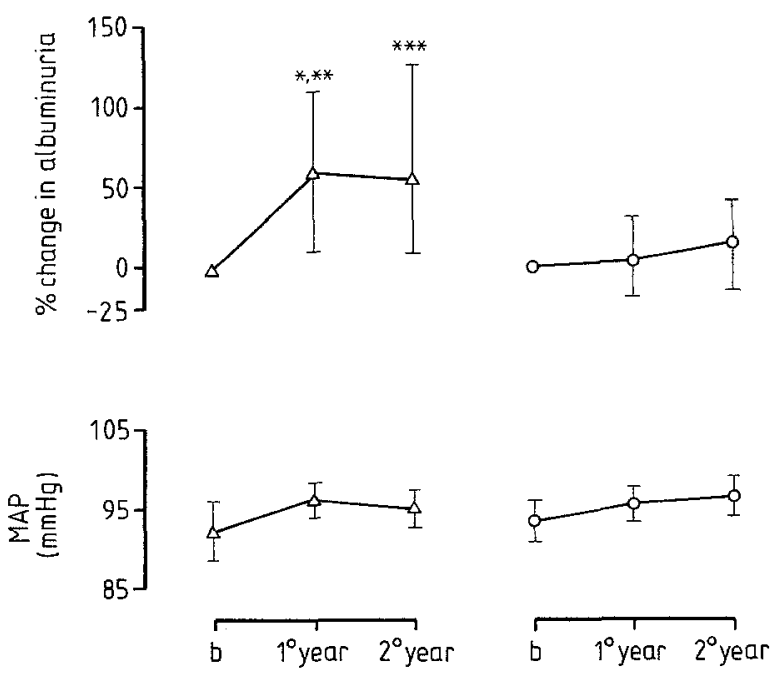

Fig. 1. Changes in albuminuria and mean arterial pressure. High linoleic acid diet group, $\Delta$; usual diet group, $O$. Measurements at baseline (b), during first $\left(1^{\circ}\right)$ and second $\left(2^{\circ}\right)$ year of the study. Changes in albuminuria as percent change (median, $95 \%$ confidence interval) from baseline. Mean arterial pressure (MAP) as mean \pm SEM. $* p<0.02$ compared to baseline; $* * p<0.05$ compared to usual diet group; $* * * p<0.01$ compared to baseline 
Table 4. Effect of dietary assignment and systemic blood pressure on progression of albuminuria during the second year of the study

UalbV $^{a}$ decrease Relative risk

increase $(n)$

(n)

\begin{tabular}{llrl}
\hline $\begin{array}{l}\text { average } \mathrm{MAP}^{\mathrm{b}} \\
\leq 95 \mathrm{mmHg}\end{array}$ & & & \\
$\mathrm{UD}^{\mathrm{c}}$ & 3 & 10 & 1.0 \\
$\mathrm{HLAD}^{\mathrm{c}}$ & 7 & 1 & $3.79(95 \% \mathrm{CI}, 1.36$ to \\
& & & $10.60)^{\mathrm{d}}$
\end{tabular}

average MAP

$>95 \mathrm{mmHg}$

$\begin{array}{llll}\text { UD } & 7 & 0 & 4.33(95 \% \mathrm{CI}, 1.60 \text { to }\end{array}$

$11.70)^{\mathrm{e}}$

$\begin{array}{llll}\text { HLAD } & 6 & 2 & 3.25(95 \% \mathrm{CI}, 1.11 \text { to } 9.48)^{d}\end{array}$

a UalbV, urinary albumin excretion rate; ${ }^{b}$ MAP, mean arterial pressure; ${ }^{c}$ UD, Type 1 (insulin-dependent) diabetic patients assigned to usual diet; HLAD, Type 1 diabetic patients assigned to high linoleic acid diet; ${ }^{\mathrm{d}} p<0.05$ and ${ }^{\mathrm{e}} p<0.01$ from UD patients with average MAP $\leq 95 \mathrm{~mm} \mathrm{Hg}$. The figures in parentheses indicate

Table 5. Renal haemodynamics

\begin{tabular}{|c|c|c|c|}
\hline & \multicolumn{3}{|c|}{ Glomerular filtration rate $\left(\mathrm{ml} \cdot \mathrm{min}^{-1} \cdot 1.73 \mathrm{~m}^{-2}\right)$} \\
\hline & baseline & 1 year & 2 years \\
\hline HLAD $(n$ & $106 \pm 27$ & $107 \pm 28$ & $103 \pm 30$ \\
\hline $\mathrm{UD}(n=20)^{\mathrm{a}}$ & $120 \pm 26$ & $118 \pm 23$ & $110 \pm 21^{\mathrm{b}}$ \\
\hline $\begin{array}{l}\text { HLAD }(n=16) \\
\mathrm{UD}(n=20)\end{array}$ & $\begin{array}{l}\text { Effective r } \\
\text { baseline } \\
455 \pm 125 \\
507 \pm 144\end{array}$ & $\begin{array}{l}\text { lplasma fl } \\
1 \text { year } \\
441 \pm 117 \\
503 \pm 137\end{array}$ & $\begin{array}{l}\left(m l \cdot \mathrm{min}^{-1} \cdot 1.73 \mathrm{~m}^{-2}\right) \\
2 \text { years } \\
430 \pm 129 \\
480 \pm 131\end{array}$ \\
\hline $\begin{array}{l}\text { HLAD }(n=16) \\
\operatorname{UD}(n=20)\end{array}$ & $\begin{array}{l}\text { Filtration } f \\
\text { baseline } \\
23.6 \pm 3.7 \\
24.1 \pm 2.8\end{array}$ & $\begin{array}{l}\text { tion }(\%) \\
1 \text { year } \\
24.6 \pm 2.9 \\
24.1 \pm 3.0\end{array}$ & $\begin{array}{l}2 \text { years } \\
24.2 \pm 3.0^{c} \\
23.3 \pm 2.5\end{array}$ \\
\hline
\end{tabular}

${ }^{a}$ HLAD, Type 1 (insulin-dependent) diabetic patients assigned to high linoleic acid diet; UD, Type 1 diabetic patients assigned to usual diet. $^{\mathrm{b}} p<0.005$ compared to baseline; ${ }^{\mathrm{c}}$ change in HLAD different from change in $\mathrm{UD}, p<0.05$. Results are given as mean $\pm \mathrm{SD}$

There were no significant differences in baseline GFR $(p>0.20), \operatorname{ERPF}(p>0.30)$ and filtration fraction $(p>0.40)$ between the groups (Table 5). Glomerular hyperfiltration (GFR $>135 \mathrm{ml} \cdot \mathrm{min}^{-1} \cdot 1.73 \mathrm{~m}^{-2}$ ) was present in three HLAD patients and in five UD patients $(p>0.80)$. In the UD group, GFR decreased after 2 years, whilst in the HLAD group, GFR remained unaltered. The ERPF tended to decline in the HLAD and the UD group ( $p<0.10$ for both groups). There was a trend for the filtration fraction to increase in the HLAD group and to decrease in the UD group, the difference in change being significant after 2 years.

Multiple regression analysis confirmed that the progression of albuminuria as well as the lack of decrease in GFR during the second year of the study were independently related to assignment to HLAD. Blood pressure during the study $(p<0.005)$, baseline $\operatorname{ERPF}(p<0.05)$ and assignment to HLAD in the patients with MAP $\leq 95 \mathrm{~mm} \mathrm{Hg}(p<0.05) \mathrm{had}$ an independent effect on the progression of albuminuria (as relative change of UalbV after logarithmic transformation). In this analysis baseline UalbV did not significantly contribute to progression of albuminuria $(p=0.54)$. The change in ERPF after 2 years $(p<0.001)$ and also assignment to HLAD $(p=0.06)$ independently contributed to the 2-year change in GFR, whereas addition to the analysis of glomerular hyperfiltration at baseline did not $(p=0.29)$. Oncotic pressure was unlikely to be responsible for the difference in renal haemodynamic changes between the HLAD and the UD groups. At baseline and after 2 years serum total protein (baseline: HLAD $68.9 \pm 2.6 \mathrm{~g} / \mathrm{l}$, UD $68.6 \pm 3.8 \mathrm{~g} / \mathrm{l}$, NS; after 2 years: HLAD $68.4 \pm 3.1 \mathrm{~g} / \mathrm{l}$, UD $67.7 \pm 3.7 \mathrm{~g} / \mathrm{l}, \mathrm{NS})$ and albumin concentration (baseline: HLAD $44.1 \pm 2.5 \mathrm{~g} / 1$, UD $44.4 \pm 3.3 \mathrm{~g} / 1, \mathrm{NS}$; after 2 years: HLAD $41.8 \pm 2.3 \mathrm{~g} / 1$, UD $42.2 \pm 3.1 \mathrm{~g} / 1, \mathrm{NS}$ ) were similar in the two groups.

\section{Lipoproteins}

Cholesterol, triglyceride and apolipoprotein levels are shown in Figure 2. In the HLAD group, total serum cholesterol decreased. HDL cholesterol decreased from $1.34 \pm 0.27 \mathrm{mmol} / \mathrm{l}$ at baseline to $1.28 \pm 0.37 \mathrm{mmol} / \mathrm{l}$ during the second year. LDL cholesterol decreased from $3.87 \pm 1.17 \mathrm{mmol} / \mathrm{l}$ to $3.66 \pm 0.75 \mathrm{mmol} / 1$ and apolipoprotein B decreased from $0.90 \pm 0.29 \mathrm{~g} / \mathrm{l}$ to $0.81 \pm 0.18 \mathrm{~g} / \mathrm{l}$. VLDL cholesterol, serum triglyceride and apolipoprotein $A_{1}$ did not change significantly. In the UD group, total serum cholesterol decreased slightly. This could be entirely accounted for by a decrease in HDL cholesterol from $1.41 \pm 0.37 \mathrm{mmol} / \mathrm{l}$ at baseline to $1.29 \pm 0.37 \mathrm{mmol} / 1$ during the second year. In this group, LDL and VLDL cholesterol, serum triglyceride, apolipoprotein $\mathrm{A}_{1}$ and $\mathrm{B}$ did not change significantly.

\section{Body weight and metabolic control}

Body weight, $\mathrm{HbA}_{1}$, blood glucose and insulin dose are shown in Figure 3. At baseline body weight was comparable in the HLAD and the UD groups. In both groups the body weight was higher during the second year, but the increase was only significant in the UD group. There were no differences in $\mathrm{HbA}_{1}$ between the groups. However, $\mathrm{HbA}_{1}$ was lower at baseline compared with the measurement which was taken when the patients were selected for and informed about the study. During the first year $\mathrm{HbA}_{1}$ was higher than at baseline in both groups, but not different from the values obtained at selection of the patients. No change in 24-h blood glucose profiles could be demonstrated. Insulin dose was comparable in the HLAD and the UD groups at baseline and did not change significantly.

\section{Discussion}

This prospective randomised study determines the longterm effects of a diet enriched in linoleic acid on albuminuria and lipid levels in Type 1 diabetic patients with elevated UalbV. An overnight UalbV above $10 \mu \mathrm{g} / \mathrm{min}$ was considered to be abnormal, because this level represents the 97.5th percentile for normal subjects in our clinic. Other studies have used a cut-off level of 15 or $20 \mu \mathrm{g} / \mathrm{min}$ obtained during the day or in 24 -h urine collections $[2,5,35]$, but urinary albumin excretion is lower at 


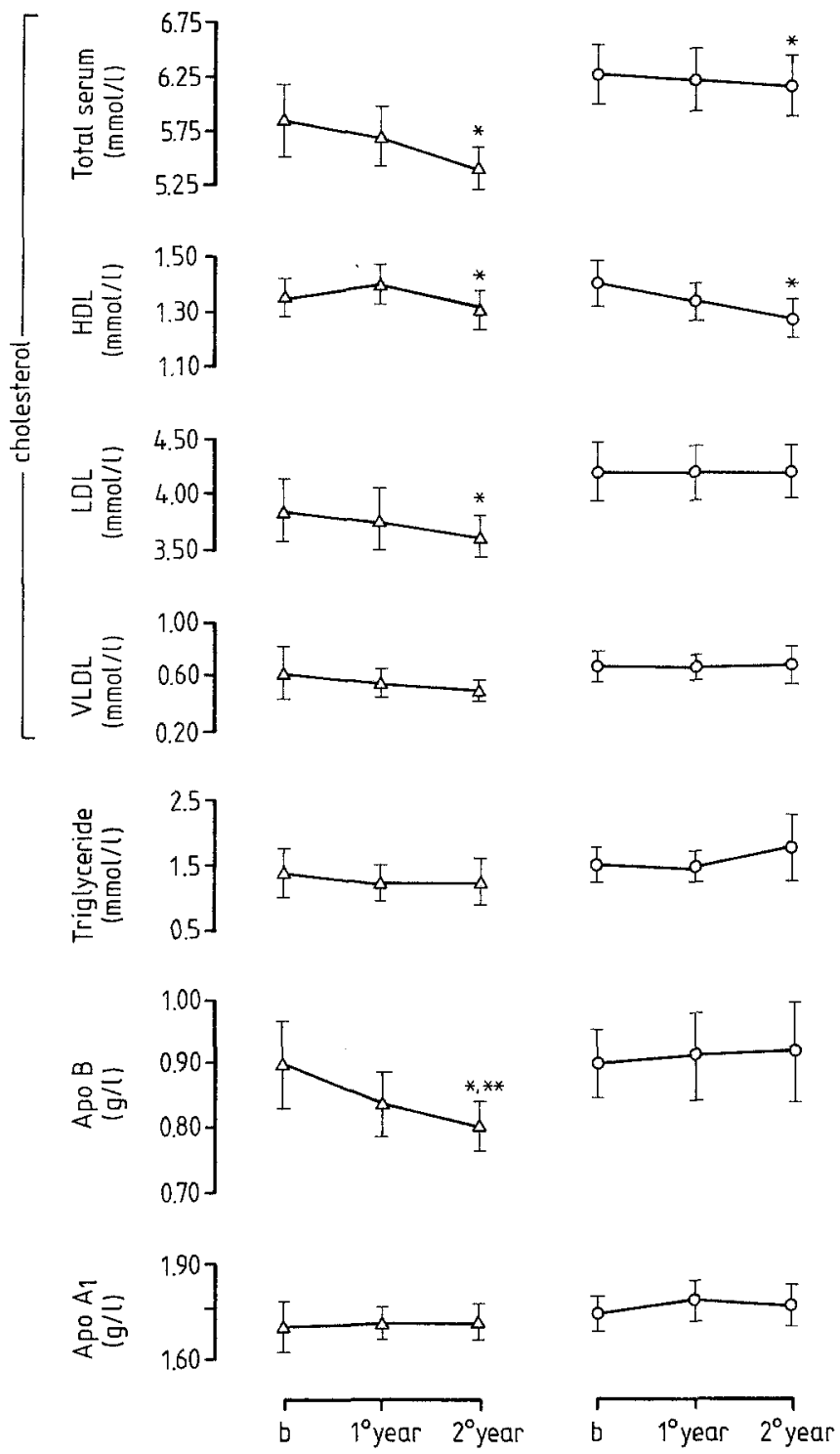

Fig. 2. Lipids and apolipoproteins. High linoleic acid diet group, $\triangle$; usual diet group, $O$. Measurements at baseline (b), during first $\left(1^{\circ}\right)$ and second $\left(2^{\circ}\right)$ year of the study. Apo denotes apolipoprotein. Data as mean \pm SEM. $* p<0.05$ compared to baseline; $* *$ change different from change in usual diet group, $p<0.05$

night [18]. Patients with minor elevations in urinary albumin excretion were thus included in the present study.

Comparison of baseline data showed similar clinical characteristics, albuminuria, blood pressure, GFR, ERPF, metabolic control and diet composition in the two study groups. Total fat-derived energy intake was rather high although the patients had been advised at diagnosis or referral to the clinic to adopt a diet with 30-35\% energy from fat. An increase in dietary $P: S$ ratio was achieved by replacement of saturated-fatty-acid-rich nutrients with linoleic-acid-rich products without changing the total fat and protein content of the diet. The compliance to the prescribed diet was good, as indicated by the dietary recall data. Plasma cholesteryl ester fatty acid analysis substantiated the increase in dietary $P: S$ ratio using the plasma linoleic acid: oleic acid ratio parameter [23]. However, perturbations in fatty acid metabolism in Type 1 diabetes will result in a variable increase in plasma cholesteryl linoleate $[36,37]$, which makes fatty acid analysis less suitable to assess dietary intake in the individual patient [38]. Plasma fatty acid analysis was therefore only used to confirm compliance in the whole group of patients.

In the control group, there was a non-significant rise in urinary albumin excretion rate of $16 \%$ during the second year of the study. This progression is comparable with an annual increase of $7 \%$ observed in conventionally treated patients [35], but is somewhat lower than the mean annual increase of $19 \%$ reported in another study [39]. In the HLAD group, albuminuria rose significantly more $(58 \%$ during the first year and $55 \%$ during the second year of the study). When subsets of patients with baseline urinary albumin excretion rate above or below $20 \mu \mathrm{g} / \mathrm{min}$ were analysed, a similar trend for accelerated albuminuria was noted with the high linoleic acid diet. In addition, risk analysis as well as multiple regression analysis indicated that both assignment to high linoleic acid diet and systemic blood pressure contributed independently to progression of albuminuria. Blood pressure tended to rise during the study in both groups. The present study therefore shows that a linoleic-acid-enriched diet does not reduce systemic blood pressure, agreeing with most clinical investigations [40]; although a blood-pressure-lowering effect of linoleic acid has been claimed [41]. Previous reports have also shown a rise in blood pressure at follow-up of microalbuminuric patients, which supports the assumption that increase in blood pressure and progression of albuminuria are concomitant $[35,39]$.

GFR decreased after 2 years in the control group. Given an observation period of only 2 years it cannot be

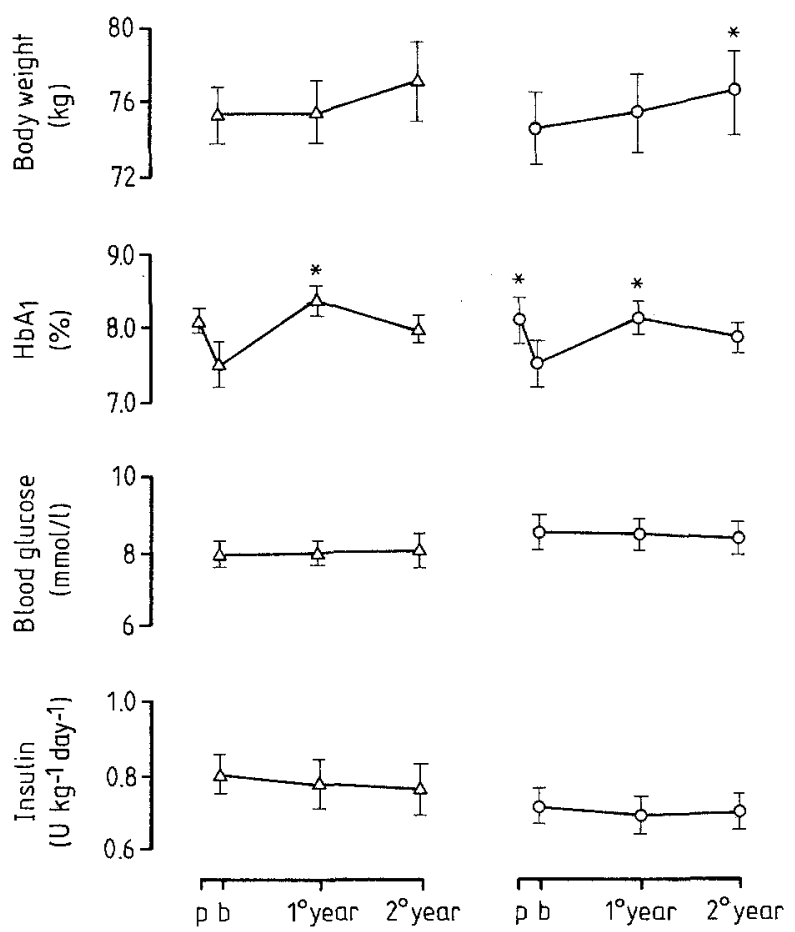

Fig.3. Body weight, metabolic control and insulin dose. High linoleic diet group, $\triangle$; usual diet group, $O$. Measurements obtained pre-randomisation (p), at baseline (b), during first $\left(1^{\circ}\right)$ and second $\left(2^{\circ}\right)$ year of the study. Data as mean \pm SEM. $* p<0.05$ compared to baseline 
discerned whether this reflects diminished glomerular hyperfiltration or deterioration of renal function. The individual changes in GFR were related to the changes in ERPF indicating the importance of renal plasma flow as a determinant of glomerular filtration [42]. Other studies have shown that GFR decreased in patients with higher levels of albuminuria [5] and that GFR declines more in patients with glomerular hyperfiltration [43]. In the HLAD group, GFR did not change and filtration fraction tended to rise. Multiple regression analysis substantiated an independent inhibiting effect of the high linoleic acid diet on the decrease in GFR. Furthermore, the difference in renal haemodynamic alterations between the two study groups could not be explained on the basis of a difference in the proportion of patients with glomerular hyperfiltration, blood pressure, colloid osmotic pressure as reflected by serum protein concentration, or metabolic control. These results would support the hypothesis that renal haemodynamic factors might be involved in the accelerated albuminuria associated with a linoleic-acid-enriched diet.

The mechanisms by which dietary linoleic acid has an effect on albuminuria and renal haemodynamic abnormalities were not explored in the present study. One possibility is that increasing linoleic acid intake alters the systemical and renal synthesis of vasoactive prostaglandins such as prostaglandin $E_{2}, I_{2}$ and thromboxanes through an effect on arachidonic acid availability in the cyclooxygenase pathway $[44,45]$. In normal subjects, creatinine clearance rose after a linoleic-acid-rich diet, possibly as the result of enhanced synthesis of the vasodilatory prostaglandin $E_{2}[12]$. Animal experiments employing partial renal ablation have also shown that increasing linoleic acid intake alters urinary prostaglandin excretion, but in these studies proteinuria was reduced [15-17]. Urinary prostaglandin $\mathrm{E}_{2}$ excretion was higher in microalbuminuric than in normoalbuminuric Type 1 diabetic patients and indomethacin reduced both prostaglandin $\mathrm{E}_{2}$ excretion and albuminuria [46]. Enhanced renal synthesis of vasodilatory prostaglandins was found to be associated with glomerular hyperfiltration in streptozotocin-induced diabetes in rats [47] and in Type 1 diabetes in man [48]. By contrast, other studies did not support a role for renal prostaglandins in glomerular hyperfiltration in Type 1 diabetic patients [ 49 , 50]. Whether altered prostaglandin synthesis is involved in the renal functional abnormalities associated with a linoleic-acid-enriched diet remains speculative at present and further study is needed.

With the linoleic-acid-enriched diet, LDL cholesterol and apolipoprotein B levels were modestly reduced whereas apolipoprotein B-containing lipoproteins did not change in the control group. These findings are in agreement with the reported reduction of LDL cholesterol observed in Type 2 (non-insulin-dependent) diabetic patients consuming a linoleic-acid-enriched diet [51]. The decrease in cholesterol intake that coincided with the increase in dietary $\mathrm{P}: \mathrm{S}$ ratio could have contributed to the LDL lowering in the present study [52]. LDL cholesterol and apolipoprotein B did not significantly decrease until the second year of the study. This apparently late effect can probably be explained by the fact that $\mathrm{HbA}_{1}$ levels were lower at baseline than at selection of patients and rose again during the first year of the study. Previous studies have shown that HDL cholesterol was lower in microalbuminuric than in normoalbuminuric Type 1 diabetic patients $[8,9]$. Thus the decline in HDL cholesterol at follow-up is not unexpected. Since HDL cholesterol decreased similarly in both study groups, it appears that increasing dietary linoleic acid intake to a $\mathrm{P}: \mathrm{S}$ ratio of 1.0 does not have an effect on HDL cholesterol in microalbuminuric patients. This should be compared with nondiabetic subjects in which an intake of linoleic acid up to 12 energy \% does not significantly lower HDL cholesterol [53], but in which a reduction in HDL cholesterol has been reported at higher intakes [54].

In conclusion, a linoleic-acid-enriched diet has a beneficial effect on atherogenic lipoproteins in Type 1 diabetic patients with elevated urinary albumin excretion. However, as albuminuria most probably reflects glomerular dysfunction, this diet does not appear to have a beneficial effect on and might even promote renal functional abnormalities. The effects of a linoleic-acid-enriched diet on cardiovascular disease and eventual deterioration of renal function in Type 1 diabetic patients with microalbuminuria remains to be established.

Acknowledgements. This study was supported by a grant from the Dutch Diabetes Research Fund. M. van Kammen, F. KranenburgNienhuis and A.Drent are acknowledged for their skillful assistance. M. van der Molen and Dr. F. A. J. Muskiet performed the plasma cholesteryl ester fatty acid analysis.

\section{References}

1. Viberti GC, Jarrett RJ, Mahmud U, Hill RD, Argyropoulos A, Keen H (1982) Microalbuminuria as a predictor of clinical nephropathy in insulin-dependent diabetes mellitus. Lancet I: 1430-1432

2. Mogensen CE, Christensen CK (1984) Predicting diabetic nephropathy in insulin-dependent patients. NEngl J Med 311:89-93

3. Mogensen CE (1990) Prediction of clinical diabetic nephropathy in IDDM patients. Alternatives to microalbuminuria? Diabetes 39: 761-767

4. Borch-Johnsen K, Kreiner S (1987) Proteinuria: value as a predictor of cardiovascular mortality in insulin-dependent diabetes mellitus. Br Med J 294: 1651-1654

5. Deckert T, Feldt-Rasmussen B, Borch-Johnsen K, Jensen T, Kofoed-Enevoldsen A (1989) Albuminuria reflects widespread vascular damage. The Steno hypothesis. Diabetologia 32:219-226

6. Vannini P, Ciavarella A, Flammini M et al. (1984) Lipid abnormalities in insulin-dependent diabetic patients with albuminuria. Diab Care 7: 151-154

7. Jensen T, Stender S, Deckert T (1988) Abnormalities in plasma concentrations of lipoproteins and fibrinogen in Type 1 (insulindependent) diabetic patients with increased urinary albumin excretion. Diabetologia 31: 142-145

8. Watts GF, Naumova R, Slavin BM et al. (1989) Serum lipids and lipoproteins in insulin-dependent diabetic patients with persistent microalbuminuria. Diab Med 6: 25-30

9. Jones SL, Close CF, Mattock MB, Jarrett RJ, Keen H, Viberti GC (1989) Plasma lipid and coagulation factor concentrations in insulin-dependent diabetics with microalbuminuria. Br Med J 298:487-490

10. Dullaart RPF, Dikkeschei LD, Doorenbos H (1989) Alterations in serum lipids and apolipoproteins in male Type 1 (insulin-dependent) diabetic patients with microalbuminuria. Diabetologia 32: 685-689

11. World Health Organisation (1985) WHO study group on diabetes mellitus. Technical report series 727 , Geneva 
12. Adam O, Wolfram G (1984) Effect of different linoleic acid intakes on prostaglandin biosynthesis and kidney function in man. Am J Clin Nutr 40: 763-770

13. Hurd ER, Johnston JM, Okita JR, MacDonald PC, Gilliam JN (1981) Prevention of glomerulonephritis and prolonged survival in New Zealand black/New Zealand white $F_{1}$ hybrid mice fed an essential fatty acid-deficient diet. J Clin Invest 67: 476 485

14. Dubois CH, Foidart JB, Dechenne CA, Mahieu PR (1982) Effects of a diet deficient in essential fatty acids on the glomerular hypercellularity occurring in the course of nephrotoxic serum nephritis in rats. Kidney Int 21 [Suppl 11]: \$39-\$45

15. Barcelli UO, Weiss M, Pollak VE (1982) Effects of a dietary prostaglandin precursor on the progression of experimentally induced chronic renal failure. J Lab Clin Med 100: 786-797

16. Heifets M, Morrisey JJ, Purkerson ML, Morrison AR, Klahr S (1987) Effect of dietary lipids on renal function in rats with subtotal nephrectomy. Kidney Int 32: 335-341

17. Clark WF, Parbtani A, Philbrick D et al. (1990) Comparative efficacy of dietary treatments on renal function in rats with subtotal nephrectomy: renal polyunsaturated fatty acid incorporation and prostaglandin excretion. Clin Nephrol 33: 25-34

18. Mogensen CE (1971) Urinary albumin excretion in early and long-term juvenile diabetes. Scand J Clin Lab Invest 28: 183-193

19. Dullaart RPF, Roelse H, Sluiter WJ, Doorenbos H (1989) Variability of albumin excretion in diabetes. Neth J Med 34: 287-296

20. Viberti GC, Jarrett RJ, Wiseman MJ (1984) Prediction diabetic nephropathy. N Engl J Med 311: 1256-1257 (Letter)

21. Van Staveren WA, Hulshof KFAM (1980) De voedingsanamnese in het voedingsonderzoek, mogelijkheden en beperkingen. Voeding 41: 228-232

22. Stichting NEVO, CIVO Institute TNO (1987) NEVO Table Zeist. Voorlichtingsbureau voor de Voeding

23. Glatz JFC, Soffers AEMF, Katan MB (1989) Fatty acid composition of serum cholesteryl esters and erythrocyte membranes as indicator of linoleic acid intake in man. Am J Clin Nutr 49:269-276

24. Maroni BJ, Steinman TI, Mitch WE (1985) A method for estimating nitrogen intake of patients with chronic renal failure. Kidney Int 27: 58-65

25. Donker AJM, Van der Hem GK, Sluiter WJ, Beekhuis H (1977) A radioisotope method for simultaneous determination of the glomerular filtration rate and the effective renal plasma flow. Neth J Med 20: 97-103

26. Dullaaxt RPF, Meijer S, Sluiter WJ, Doorenbos H (1990) Renal haemodynamic changes in response to moderate hyperglycaemia in Type 1 (insulin-dependent) diabetes mellitus. Eur $\mathbf{J}$ Clin Invest 20: 208-213

27. Fliickiger R, Winterhalter KH (1976) In vitro synthesis of haemoglobin Alc. FEBS Lett 71: 356-360

28. Lopes-Virella MF, Stone P, Ellis S, Colwell JA (1977) Cholesterol determinations in high density lipoproteins separated by three different methods. Clin Chem 23: 882-884

29. Lie RF, Schmitz JM, Pierre KJ, Gochman N (1976) Cholesterol oxidase based determination by continuous flow analysis of total and free cholesterol in serum. Clin Chem 22: 1627-1630

30. Buculo G, David H (1973) Quantitative determination of serum triglycerides by use of enzymes. Clin Chem 19: 475-482

31. Friedewald WT, Levy RI, Fredrickson DS (1972) Estimation of the concentration of low-density lipoprotein cholesterol in plas$\mathrm{ma}$, without use of the preparative ultracentrifuge. Clin Chem 18: 499-502

32. Muskiet FAJ, Van Doornaal JJ, Martini IA, Wolthers BG, Van der Slik W (1983) Capillary gas chromatographic profiling of total long-chain fatty acids and cholesterol in biological materials. J Chromatogr Biomed Appl 278: 231-244

33. Siegel S (1956) Nonparametric statistics for the behavorial sciences. McGraw-Hill, New York

34. Duncan DB (1955) Multiple range and multiple F-tests. Biometrics 11: $1-42$

35. Feldt-Rasmussen B, Mathiesen ER, Deckert T (1986) Effect of two years strict metabolic control on progression of incipient nephropathy in insulin-dependent diabetes. Lancet II: 1300-1304
36. Tilvis RS, Miettinen TA (1985) Fatty acid compositions of serum lipids, erythrocytes and platelets in insulin-dependent diabetic women. J Clin Endcrinol Metab 61: 741-745

37. Van Doormaal JJ (1990) Linoleic acid metabolism in diabetes mellitus. Neth J Med 37: 207-214

38. Van Doormaal JJ, Muskiet FAJ, Dullaart RPF, Beusekamp BJ, Doorenbos H (1989) The fatty acid composition of plasma cholesterol esters does not adequately reflect dietary intake of linoleic acid and total w3 fatty acid in the individual patient with insulin-dependent diabetes mellitus. Eur J Clin Invest 19: 31 (Abstract)

39. Christensen CK, Mogensen CF (1985) The course of incipient diabetic nephropathy: studies of aibumin excretion and blood pressure. Diab Med 2: 97-102

40. Sacks FM (1989) Dietary fats and blood pressure: a critical review of the evidence. Nutr Rev 47: 291-300

41. Heagerty AM, Ollerenshaw JD, Robertson DI, Bing RF, Swales JD (1986) Influence of dietary linoleic acid on leucocyte sodium transport and blood pressure. Br Med J 293: 295-297

42. Brenner BM, Humes HD (1977) Mechanics of glomerular uitrafiltration. N Engl J Med 297: 148-154

43. Jones SL, Wiseman MJ, Viberti GC (1991) Glomerular hyperfiltration as a risk factor for diabetic nephropathy: five-year report of a prospective study. Diabetologia 34: 59-60 (Letter)

44. Barcelli U, Pollak VE (1985) Is there a role for polyunsaturated fatty acids in the prevention of renal disease and renal failure. Nephron 41: 209-212

45. Klahr S, Harris K (1989) Role of dietary lipids and renal eicosanoids on the progression of renal disease. Kidney Int 36 [Suppl 27]: S27-S31

46. Mathiesen ER, Hommel E, Olsen UB, Parving HH (1988) Elevated urinary prostaglandin excretion and the effect of indomethacin on renal function in incipient diabetic nephropathy. Diab Med 5: 145-149

47. Craven PA, DeRubertis FR (1989) Role of local prostaglandin and thromboxane production in the regulation of glomerular filtration rate in the rat with streptozotocin-induced diabetes. J Lab Clin Med 113: 674-681

48. Viberti GC, Benigni A, Bognetti E, Remuzzi G, Wiseman MJ (1989) Glomerular hyperfiltration and urinary prostaglandins in Type 1 diabetes mellitus. Diab Med 6:219-223

49. Sandahl-Christiansen J, Feldt-Rasmussen B, Parving HH (1985) Short-term inhibition of prostaglandin synthesis has no effect on the elevated glomerular filtration rate of early insulin-dependent diabetes. Diab Med 2: 17-20

50. Jenkins D AS, Craig K. Collier A, Watson ML, Clarke BF (1989) Evidence against a role for prostaglandins in sustaining renal hyperfiltration in Type 1 diabetes mellitus. Diab Med 6: 502-505

51. Heine RJ, Mulder C, Popp-Snijders C, Van der Meer J, Van der Veen EA (1989) Linoleic-acid-enriched diet: long-term effects on serum lipoprotein and apolipoprotein concentration and insulin sensitivity in noninsulin-dependent diabetic patients. Am J Clin Nutr 49: 448-456

52. Grundy SM (1987) Dietary therapy for hyperlipidemia. Baillière's Clin Endocrinol Metab 1: 667-698

53. Mensink RP, Katan MB (1989) Effect of a diet enriched with monounsaturated or polyunsaturated fatty acids on levels of lowdensity and high-density cholesterol in healthy women and men. New Engl J Med 321: 436-441

54. Mattson FH, Grundy SM (1985) Comparison of dietary saturated, monounsaturated, and polyunsaturated fatty acids on plasma lipids and lipoproteins in man. J Lipid Res 26: 194-202

Received: 18 April 1991

and in revised form: 9 October 1991

Dr. R.P.F.Dullaart

Department of Endocrinology

University Hospital Groningen

Oostersingel 59

NL-9713 EZ Groningen

The Netherlands 